\title{
A Study on Teachers' Views on the Use of Technology to Improve Physics Education in High Schools*
}

\author{
Aytekin Erdem \\ Correspondence: Aytekin Erdem, Tekirdag Namik Kemal University, Vocational School of Technical Sciences, \\ Department of Electronics and Automation, 59030 Suleymanpasa-Tekirdag, Turkey.
}

\author{
Received: February 12, $2019 \quad$ Accepted: March 11, $2019 \quad$ Online Published: March 13, 2019 \\ doi:10.11114/jets.v7i4.4019 URL: https://doi.org/10.11114/jets.v7i4.4019
}

\begin{abstract}
This study was carried out to determine teacher views on the use of technology to improve physics education in high schools. The sample of the study is 238 volunteer physics teachers. The study was carried out with the survey model and a five point Likert Scale was used in the study. The scale has a reliability coefficient of 0.92 . Descriptive and inferential statistical techniques were used to analyze the data obtained from the scale. According to the results of the analysis, it was determined that teachers strongly agreed with all six of the articles except one of the views within the dimension "suggestions on teacher competence and technology-based subject discourse" and with only one out of the five articles within the dimension "recommendations for performing technology-assisted laboratory activities." In addition, it has been determined that significant change in teachers' views did not occur regarding the use of technology to improve physics education according to different individual characteristics. However, it has been determined that there is a significant positive difference with those in high need of professional development.
\end{abstract}

Keywords: high school, physics education, teacher, technological device and product, improvement

\section{Introduction}

Today, technology is widely used in education as it is in every field of our everyday life. For this reason, the use of devices and products relating to information technologies in classrooms and extracurricular learning activities is increasing throughout the teaching process. On the other hand, students describe physics as a difficult subject to learn (Ornek, Robinson \& Haugan, 2008). It is thought that students may take advantage of technological opportunities in order to overcome learning difficulties in physics. Physics is a branch of science that contains many concepts and can hence be explained by these concepts. Physics is perceived as a difficult lesson when, instead of trying to fully understand these concepts themselves and the relationship between each of them, numerical operations are carried out merely by looking at these concepts as formulas made up of symbols (Bozkurt \& Sarikoc, 2008). The inability of students to perceive these concepts accurately leads to misconceptions which are consequently difficult to overcome (Atasoy \& Akdeniz, 2007; Gulçiçek \& Yagbasan, 2004; Kaltakci \& Didis, 2007; Kim, Choi \& Song, 2007; Lawrenz, 1986; Styer, 1996; Sung \& Rudowicz, 2003; Van Hise, 1988; Yıldız \& Buyukkasap, 2006; Zeilik, Schau \& Mattern, 1998). However, simulations, which are a product of technology, contribute positively to the correction of misconceptions and to the development of concepts, and it is also emphasized by studies that this increases students' academic achievement (Bozkurt \& Sarikoc, 2008; Demircioglu \& Geban, 1996; Gul \& Yesilyurt, 2011; Guven \& Sulun, 2012; Jimoyiannis \& Komis, 2001; Karamustafaoglu, Aydın \& Ozmen, 2005; Kolcak, Mogol \& Unsal, 2014; Sarabando, Cravino \& Soares, 2014; Wang, Wu \& Hsu, 2017; Windschitl \& Andre, 1998). For this reason, teachers need to believe that technology can be used in the learning of physics education and must be willing to implement these beliefs.

Research conducted shows that teachers believe that technology contributes to students' learning, but they are not willing or successful in integrating technology in to their lessons. Therefore, it is stated that there is a discrepancy between the beliefs of teachers and their practices in the teaching process (Batane \& Ngwako, 2017). Teachers' beliefs on technology are influenced by their teaching philosophy. Teachers' existing teaching beliefs form their resistance to adopting new technologies (Sugar, Crawley \& Fine, 2004, cited Norton, McRobbie \& Cooper, 2000). However, when technology is

\footnotetext{
*This study is supported by Tekirdag Namik Kemal University Scientific Research Projects (SRP) unit NKUBAP.00.MB.AR.13. No.06. created from the research project.
} 
used as a tool, the teacher makes it easier for the student to learn and students can have an active role in the learning process. Successful integration of technology in to teaching is the result of teachers' simultaneous conversion of beliefs and philosophies (Sugar et al., 2004; cited Windschitl \& Sahl, 2002).

\subsection{Literature Review}

In order to improve education at all levels at schools and in the field of learning and to increase teacher quality and productivity; improving competence and reorganizing and enriching the teaching environment in accordance with the student-centered approach is necessary. Therefore, it is expected that teachers are helped in order to improve themselves (NCETE, 1985; Ustuner, Ersoy \& Sancar, 2000). In order for the physics teacher to perform his/her duties, while playing the new role in the latest "Physics Curriculum Program" (Ministry of National Education, 2018), they have to acquire new skills specifically with a constructivist approach and use technology [computer, smart board, tablet computer, advanced calculator, etc.] to prepare teaching materials on various teaching subjects and to use teaching technologies in a useful way by enabling students to participate effectively in teaching-learning activities. In Turkey, prior to the implementation of the project "Enhancing Opportunities and Improving Technology (Fatih) Project" some technical equipment had been provided to some of the schools. With the Fatih Project, technological equipment such as interactive boards and tablet computers, etc. were sent to and set up at more schools. In order for these devices to be used effectively by the students, solutions are being sought out with regards to the problem of teacher's competence by acquiring techno-pedagogical expertise (Ersoy, Erdem \& Uzal, 2010). Therefore, teachers should be offered effective in-service training opportunities so that they can prepare technology-based materials by identifying traditional and new types of activities that are performed by teachers in a classroom environment and use these materials in their classrooms or laboratories. It is emphasized that both in Turkey and in many other countries, teachers have difficulty with integrating technology in to their classes (Demir, Ozmantar, Bingolbali \& Bozkurt, 2011, cited Bigimlas, 2009; Choy, Wong \& Gao, 2008; Oncu, Delialioglu \& Brown, 2008). Peterson (1999), it is thought that the current lack of hardware in schools, the absence of computers/hardware, the shortage of consultant staff to provide guidance to teachers, the inadequacy of professional development in the field of technology, the shortcoming of students who do not use the equipment in a protective and rigorous way, complaints regarding time constraint due to the fact that teachers fail to effectively manage time and the fact that teachers are not competent in the field of information technology contribute to the reason of why teachers do not follow technological developments and are not able to implement these developments (Zengin, 2005).

In our country, a training project has been developed in order for the effective use of technology in the classroom, to eliminate the inequality of opportunities between schools in terms of technological hardware and to enable teachers to integrate technology more easily in to their classes. The Fatih Project, which was carried out in cooperation with the Ministry of Education and the Ministry of Transport, provided technological equipment to schools and professional development programs related to the use of this equipment to teachers. When the literature is examined, it is observed that the research on the Fatih Project, which is applied in the education system, has been carried out in our country in recent years. Some of these studies are related to (Aktas, Gokoglu, Turgut \& Karal, 2014; Ayvaci, Bakirci \& Basak, 2014; Banoglu, Madenoglu, Uysal \& Dede, 2014; Bilici, 2011; Daghan, Kibar, Akkoyunlu \& Baskan, 2015; Dursun, Kuzu, Kurt, Gullupinar \& Gultekin, 2013; Gorhan \& Oncu,2015; Gunbayi \& Yoruk, 2014; Gurol, Donmus \& Arslan, 2012; Pamuk, Cakir, Ergun, Yilmaz \& Ayas, 2013) the study of the views of teachers and school administrators on the project. In these studies, suggestions on solutions to the problems that make it difficult for project equipment to be used by teachers and students and for it to be integrated in to the classrooms were presented.

Although a study (Erdem \& Uzal, 2018) can be found in Turkish literature on the use of technology in improving physics education, there is no study on this subject covering teacher's views. The research was carried out in order to eliminate this gap in the literature. Using technology effectively in physics courses has gained importance since students have difficulty learning physics subjects. Therefore, the aim of the research is to determine the views of physics teachers on the use of technology in improving physics education in high schools. This research is limited to the 238 physics teachers in some high schools in the province of Kocaeli during the 2014-2015 academic year, and their answers to the questions in the data collection tool.

\subsection{Research Question}

The answers to the following questions were investigated in this study.

1) At what stage are teachers' views on technology in terms of improving physics education?

2) Do the demographic characteristics of teachers (seniority, gender, computer literacy and the need for professional development) effect their views on technology in terms of improving physics education? 


\section{Method}

\subsection{Research Design}

In the study the survey model was utilized. With this model, each situation is examined within its current state. The individual, object or subject that is the subject of the study, is described in its existing form without any change to its environment (Karasar, 1999; Cepni, 2014).

\subsection{Population and Sample}

In the 2014-2015 academic year, physics teachers in the city of Kocaeli were designated as the population of the study, and the sample consisted of 238 physics teachers who were randomly chosen among a few of the high schools in the Kocaeli city center and some other cities.

\subsection{Data Collection Tool}

In order to obtain data for the purpose of this study, a scale covering a variety of views was developed by a research specialist. The scale has the following characteristics:

\subsubsection{TVOUTTIPE (Teacher Views on Using Technology to Improve Physics Education) Scale}

This scale is a five-Likert scale that includes teachers' views on the use of technology in improving physics education. The scale consists of two sub-factors and a total of 12 items. These items are under the following factors: "Recommendations on teacher competence and technology-based subject discourse" and "Recommendations for the realization of technology-based laboratory activities." The first factor is of a 0.91 and the second factor is of a 0.81 reliability coefficient. The reliability coefficient of the scale is 0.92 . The developed items of the scale are rated as "[1] Strongly disagree", "[2] Disagree", "[3] I have no idea", "[4] Agree”, "[5] Strongly Agree.

No reverse-encoded items were found on the TVOUTTIPE scale. In this case, the lowest total score to be determined as a result of the measurement is 12 and the highest total score is 60 . There are seven items under the factor of recommendations on teacher competence and technology-based subject discourse and five items under recommendations for the realization of technology-based laboratory activities. The discrimination ability of these items ranges from 0.464 to 0.677 . An expert opinion was consulted to determine whether the measurement tool could collect data for the purpose of the study.

\section{Results}

The data were compiled with the help of 238 randomly determined physics teachers using a newly developed measuring tool. Research data were analyzed with the SPSS data analysis program using descriptive and inferential statistical techniques.

\subsection{Demographic Information on Teachers}

In order to obtain information on the background of the participating teachers, some questions and professional experiences (seniority) were asked. The information obtained is summarized below.

It was observed that out of the 238 physics teachers $158(66.4 \%)$ consisted of male teachers and 80 (33.6\%) of female teachers. When the seniority of the teachers is looked at $23(9.7 \%)$ of the teachers have $0-5$ years, $20(8.4 \%)$ have 6-11 years, $71(29.8 \%)$ have $12-17$ years, $83(35.7 \%)$ have $18-23$ years and $39(16.4 \%)$ had over 24 years of seniority. It was observed that out of the 238 physics teachers, $158(66.4 \%)$ consisted of male teachers and $80(33.6 \%)$ of female teachers. When the seniority of the teachers is looked at $23(9.7 \%)$ of the teachers have 0-5 years, $20(8.4 \%)$ have 6-11 years, $71(29.8 \%)$ have $12-17$ years, $83(35.7 \%)$ have $18-23$ years and $39(16.4 \%)$ had over 24 years of seniority. When we look at the computer literacy of teachers, they stated that $4(1.7 \%)$ of them were weak, $66(27.7 \%)$ were average, $118(49.6 \%)$ were good and $50(21.0 \%)$ were very good at computer literacy. As far as the levels of professional development needs of teachers, they stated that $3(1.2 \%)$ had none $79(33.2 \%)$ had low, $118(49.6 \%)$ had medium and $38(16.0 \%)$ had high needs.

\subsection{Analysis of Data and Results-I: Descriptive Statistics}

This section contains the results and comments related to teacher's suggestions for the use of technology in improving physics education.

The weighted arithmetic mean was determined as [4.20 - 5.00] = 'I strongly agree,' [3.40 - 4.19] = 'I agree,' [2.60 - 3.39] $=$ 'I have no idea,' $[1.80-2.59]=$ 'I disagree' and $[1.00-1.79]=$ 'I strongly disagree.'

In calculating the range of scores of the assessment scale, the interval of the range of the arithmetic mean was obtained based on the gap range $=$ sequence width $/$ number of groups to be taken into account $=(5-1) / 5=4 / 5=0.8 /$ and this is given in Table 1. 
Table 1. Range of Weighted Arithmetic Means

\begin{tabular}{lll}
\hline Weight & Variants & Ranges \\
\hline 5 & I strongly agree & $4.20-5.00$ \\
4 & I agree & $3.40-4.19$ \\
3 & I have no idea & $2.60-3.39$ \\
2 & I disagree & $1.80-2.59$ \\
1 & I strongly disagree & $1.00-1.79$
\end{tabular}

Rough scores obtained from the scale were first calculated as $\mathrm{Z}$ points and then $\mathrm{T}$ points, then the rough scores were standardized and transformed in to equal ranges. $\mathrm{T}$ scores were used in the statistical analysis.

In order to determine whether the scores obtained from the scale show normal distribution, central-dispersion criteria were determined $(M=\overline{\mathrm{x}}=50.1 ; M d n=48.0 ;$ Mode $=47.6)$, the coefficient of skewness (Skewness $=0.29)$ and standard error (Std. Error of Skewness $=0.16$ ) ratio was 1.81. The coefficient of kurtosis (Kurtosis $=-0.36$ ) and standard error (Std. Error of Kurtosis=0.31) ratio was -1.16 . The distribution can be deemed normal because these values remain between $\alpha=0.05(-1.96)$ and (+1.96). In addition, a histogram graph of the scores obtained was formed. In respect to the results, it can be assumed that the points did not show a significant deviation from the normal distribution (Can, 2014).

\subsubsection{Teachers' Views on Using Technology to Improve Physics Education}

The degrees of opinions of physics teachers participating in the research on the use of technology in improving physics education is shown in Table 2 .

Table 2. Descriptive statistics of teachers' recommendations on using technology to improve physics education

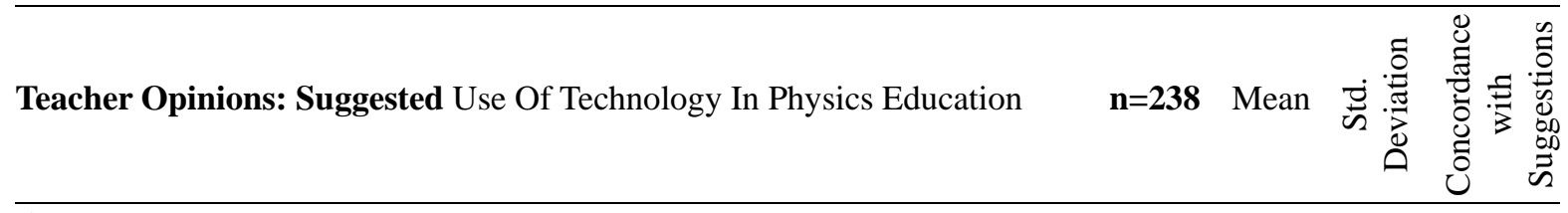

\section{Suggestions on teacher competence and technology-based subject discourse}

Teachers' knowledge/skills on using technology in the classroom should be developed $\begin{array}{rl}4.47 & 0.63\end{array}$

Animation (Animation-Flash, etc.) in education software (applets) $\quad$ should be taken $\begin{array}{lll}4.33 & 0.58\end{array}$ advantage of

Laboratories should be equipped with technology

$4.30 \quad 0.57$

$4.28 \quad 0.67$

All technologies of education should be further taken advantage of

Teaching software ("interactive Physics", etc.) simulation programs should be used

$4.280 .63 \stackrel{0}{=}$

Written and visual texts should be used in internet network

$4.28 \quad 0.55$

A variety of software for use on Tablet PCs should be utilized

$4.07 \quad 0.73$

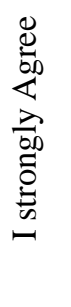

\section{Recommendations for performing technology-assisted laboratory activities}

LCD panels (interactive board) should be used in the classrooms

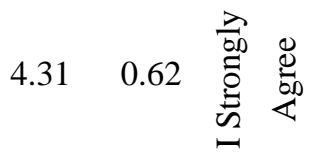

Microcomputer-based laboratories (MBL-Microcomputer based laboratory) should be $3.95 \quad 0.76$ utilized

The mobile science laboratory (Nova 5000 etc.) should be utilized

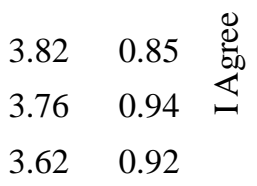

Tablet PCs should be used in subject discourse

$3.62-0.92$

Advanced (graph and CAS) calculators should be utilized

When the values of Table 2 are examined, it is understood that teachers strongly agree with the suggestions that 
"Teachers' knowledge/skills on using technology in the classroom should be developed $(M=4.47)$, " "Animation (Animation-Flash, etc.) of education software (applets) should take advantage of $(M=4.33)$," "Laboratories should be equipped with technology $(M=4.30)$," "All technologies of education should be further taken advantage of $(M=$ 4.28)," "Teaching software (Interactive Physics, etc.) simulation programs should be used $(M=4.28)$ " and "Written and visual texts should be used from the internet network $(M=4.28)$ " and that they agree with the suggestion that "A variety of software for use on Tablet PCs should be utilized $(M=4.07)$," found under the factor suggestions on teacher competence and technology-based subject discourse. Under the factor; Recommendations for performing technology-assisted laboratory activities, teachers strongly agree with the suggestion that " $L C D$ panels (interactive board) should be used in the classrooms $(M=4.31)$ " and that they agree with the suggestions that "Microcomputer-based laboratories (MBL-Microcomputer based laboratory) should be utilized $(M=3.95)$," "The mobile science laboratory (Nova 5000 etc.) should be utilized $(M=3.82)$," "Tablet PCs should be used in subject discourse $(M=3.76)$," and that "Advanced (graph and CAS) calculators should be utilized $(M=3.62) . "$

It can be interpreted that physics teachers think there are deficiencies in technology-based physics instruction because they strongly agree with the items under the factor of suggestions on teacher competence and technology-based subject discourse and the item "laboratories should be equipped with technology" under the factor of recommendations for performing technology-based laboratory activities. Teachers' suggestions for improving their knowledge and skills in using technology in classrooms may indicate that they assume that their knowledge and skills in integrating technology in to physics instruction is not yet sufficient, but are willing to improve themselves in this matter. The fact that teachers suggest that is it necessary to use interactive boards more effectively in the explanation of physics topics, benefit from animation (animation-flash etc.) applets, further take advantage of educational technologies, benefit from written and visual texts on the internet, utilize MS programs (Word, Excel, PowerPoint etc.), utilize instructional software (Interactive Physics i.e. simulation programs) and to make use of software prepared for use on LCD screens, shows that they think there are deficiencies regarding these issues and that these deficiencies should be addressed and hence shows that they are aware that technology-based physics teaching in high schools should be improved.

\subsection{Analysis of Data and Results-II: Inferential Statistics}

In this section, there are results and comments on whether there is a difference between the suggestions of the teachers on the use of technology to improve physics education in schools, and their demographic characteristics. Table 3 shows the scores from the scale for the normalcy test in terms of the gender.

Table 3. TRUTPE Scale Score Results of the Gender-Based Normalcy Test

\begin{tabular}{llllllll}
\hline & \multicolumn{3}{l}{ Kolmogorov-Smirnov $^{\mathrm{a}}$} & \multicolumn{3}{l}{ Shapiro-Wilk } \\
\hline \multirow{3}{*}{ TUTFE } & Gender & Statistics & $\mathrm{df}$ & Sig. & Statistics & $\mathrm{df}$ & Sig. \\
& Male & 0.137 & 158 & .000 & 0.955 & 158 & .000 \\
& Female & 0.177 & 80 & .000 & 0.915 & 80 & .000 \\
\hline
\end{tabular}

\section{a. Lilliefors Significance Correction}

The distribution of the scores of both men $(D(158)=0.137, p=.000)$ and women $(D(80)=0.177, p=.000)$, TRUTFE (Teachers' Recommendations for the Use of Technology in Physics Education) did not have a normal distribution ${ }^{1}$. For this reason, the non-parametric Mann Whitney U-test (Mann Whitney U-test for Independent Samples) was applied for unrelated measurements.

Table 4. Scale Score Results of the Mann-Whitney U-Test by Gender

\begin{tabular}{llllll}
\hline Gender & $\mathrm{n}$ & Mean Rank & Sum of Ranks & $\mathrm{U}$ & $\mathrm{p}$ \\
\hline Male & 158 & 118.60 & 18738.50 & 6177.500 & .776 \\
Female & 80 & 121.28 & 9702.50 & &
\end{tabular}

Table 4 shows that there is no significant difference between teachers' views on the use of technology to improve physics education according to gender $(U=6177.500, p>.05)$. The absence of any difference between the views of male and female teachers on the use of technology in improving physics education may suggest that both male and female teachers have the same perspective on the integration of technology in to physics classes.

\footnotetext{
${ }^{1}$ When the selected sample size is taken into consideration $(\mathrm{n} \geq 51)$ the Kolmogorov-Smirnov normality test results (N $\leq 50$ ) and the Shapiro-Wilk test results should be taken into consideration (Buyukozturk, 2012).
} 
Table 5. TRUTPE Scale Score Results of the Normalcy Test According to the Seniority Year

\begin{tabular}{llllllll}
\hline & \multicolumn{5}{l}{ Kolmogorov-Smirnov $^{\mathrm{a}}$} & \multicolumn{3}{l}{ Shapiro-Wilk } \\
\hline \multirow{3}{*}{ TUTFE } & Seniority Year & Statistics & $\mathrm{df}$ & Sig. & Statistics & $\mathrm{df}$ & Sig. \\
& 0-5 years & 0.163 & 23 & .113 & 0.916 & 23 & .055 \\
\cline { 2 - 7 } 6-11 years & 0.188 & 20 & .063 & 0.930 & 20 & .155 \\
& 12-17 years & 0.157 & 71 & .000 & 0.923 & 71 & .000 \\
& 18-23 years & 0.173 & 85 & .000 & 0.927 & 85 & .000 \\
& 24 years and & 0.123 & 39 & .140 & 0.983 & 39 & .811 \\
& & & & & &
\end{tabular}

a. Lilliefors Significance Correction

Out of the teachers with seniority $0-5$ years $(D(23)=0.1163, p=.113), 6-11$ years $(D(20)=0.188, p=.063), 12-17$ years $(D(71)=0.157, p=.000), 18-23$ years $(D(85)=0.173, p=.000)$ and 24 years and above $(D(39)=0.123, p$ $=.140$ ), because the teachers with 12-17 years and 18-23 years had non-normal distribution, it is understood that the TRUTPE scale is not suitable for normal distribution. For this reason, the non-parametric Kruskal Wallis h-test (Kruskal Wallis H-Test for Independent Samples) was applied for unrelated measurements.

Table 6. Results of the TRUTPE Scale Scores of the Kruskal Wallis Test According to Seniority

\begin{tabular}{lllllll}
\hline Seniority Year & $\mathrm{n}$ & Mean Rank & df & $\chi^{2}$ & $\mathrm{p}$ & $\begin{array}{l}\text { Significant } \\
\text { Difference }\end{array}$ \\
\hline 0-5 years & 23 & 130.76 & 4 & 2.852 & 0.583 & None \\
6-11 years & 20 & 108.70 & & & & \\
12-17 years & 71 & 127.33 & & & & \\
18-23 years & 85 & 116.56 & & & & \\
$\begin{array}{l}\text { 24 years and } \\
\text { above }\end{array}$ & 39 & 110.55 & & & & \\
\hline
\end{tabular}

According to Table 6, there is no significant difference between the seniority years and the teachers' views on technology for improving physics education $\left(\chi^{2}(d f=4, \mathrm{n}=238)=2.852, p>.05\right)$. From this result, it is understood that teachers' views on the use of technology in improving physics education do not change according to their seniority years. It can be interpreted that this result is due to the fact that the low senior managers acquired knowledge and skills in technology during the in-service training period, and the senior teachers became compatible with technology through the in-service training activities they participated in during the implementation of the Fatih Project in schools.

Table 7. TVOUTTIPE Scale Scores Normalcy Test Results According to Computer Literacy Levels

\begin{tabular}{llllllll}
\hline Computer Literacy Levels & \multicolumn{3}{l}{ Kolmogorov-Smirnov $^{\mathrm{a}}$} & \multicolumn{5}{l}{ Shapiro-Wilk } \\
\hline \multirow{3}{*}{ TVOUTTIPE } & Level & Statistics & $\mathrm{df}$ & Sig. & Statistics & $\mathrm{df}$ & Sig. \\
& Weak & 0.241 & 4 &. & 0.903 & 4 & .444 \\
\cline { 2 - 8 } & Average & 0.206 & 66 & .000 & 0.931 & 66 & .001 \\
& Good & 0.142 & 118 & .000 & 0.942 & 118 & .000 \\
& Very good & 0.144 & 50 & .011 & 0.945 & 50 & .021 \\
\hline
\end{tabular}

a. Lilliefors Significance Correction

The computer literacy levels of teachers who are weak $(D(4)=0.903, p=.444)$, average $(D(66)=0.206, p=.000)$, $\operatorname{good}(D(118)=0.142, p=.000)$ and very $\operatorname{good}(D(50)=0.144, p=.011)$ were observed to have non-normal distribution of the TRUTPE scale points. For this reason, non-parametric Kruskal Wallis h-test (Kruskal Wallis H-Test for Independent samples) was applied for unrelated measurements. 
Table 8. The Scale Score of the Kruskal Wallis Test Results based on Computer Literacy

\begin{tabular}{lllllll}
\hline $\begin{array}{l}\text { Levels of } \\
\text { Computer } \\
\text { Literacy }\end{array}$ & $\mathrm{n}$ & Mean Rank & df & $\chi^{2}$ & $\mathrm{p}$ & $\begin{array}{l}\text { Significant } \\
\text { Difference }\end{array}$ \\
\hline Weak & 4 & 108.00 & 3 & 3.035 & .386 & None \\
Average & 66 & 115.64 & & & & \\
Good & 118 & 115.73 & & & & \\
Very good & 50 & 134.42 & & & & \\
\hline
\end{tabular}

According to Table 8, there was no significant difference between computer literacy levels and teachers' views on technology to improve physics education $\left(\chi^{2}(d f=3, \mathrm{n}=238)=3.035, p>.05\right)$. This result shows that there is no difference between the teachers' views on the use of technology to improve physics education and the levels of computer literacy.

Table 9. Scale Scores of the Normalcy Test Results According to the need for Professional Development

\begin{tabular}{llllllll}
\hline Need for Professional Development & \multicolumn{6}{l}{ Kolmogorov-Smirnov $^{\mathrm{a}}$} & \multicolumn{3}{l}{ Shapiro-Wilk } \\
\hline \multirow{3}{*}{ TVOUTTIPE } & Need & Statistics & df & Sig. & Statistics & df & Sig. \\
\cline { 2 - 8 } & None & 0.311 & 3 &. & 0.898 & 3 & .379 \\
\cline { 2 - 8 } & Low & 0.119 & 79 & .007 & 0.955 & 79 & .007 \\
& Medium & 0.159 & 118 & .000 & 0.956 & 118 & .001 \\
& High & 0.208 & 38 & .000 & 0.843 & 38 & .000 \\
\hline
\end{tabular}

\section{a. Lilliefors Significance Correction}

It is understood that out of the teachers with no need for vocational development $(D(3)=0.898, p=.379)$, low need $(D(79)=0.119, p=.007)$, high need $(D(118)=0.159, p=.000)$, medium need $(D(38)=0.208, p=.000)$ other than the teachers with no need for professional development, the TRUTPE scale scores were understood to have non-normal distribution. For this reason, the non-parametric Wallis H-test (Kruskal Wallis H-Test for Independent Samples) was applied for unrelated measurements.

Table 10. Scale Scores of the Kruskal Wallis Test According to the Need for Professional Development

\begin{tabular}{lllllll}
\hline Professional Development Need & $\mathrm{n}$ & Mean Rank & $\mathrm{df}$ & $\chi^{2}$ & $\mathrm{p}$ & Significant Difference \\
\hline None & 3 & 138.83 & 3 & 8.999 & .029 & High-Medium; High -Low \\
Low & 79 & 111.37 & & & & \\
Medium & 118 & 114.88 & & & & \\
High & 38 & 149.24 & & & & \\
\hline
\end{tabular}

As shown in Table 10 by the scores on the TVOUTTIPE scale, there is a significant difference in teachers views on suggestions for using technology to improve physics education and their needs for professional developmental, $\chi^{2}(d f=$ $3, \mathrm{n}=238)=8.999, p<.05$. A Mann Whitney U-test was performed on the groups to find the root of the discrepancy. As a result of the implementation of the tests, it was determined that teachers who have high professional development needs have more positive opinions than those who have low professional development needs and the difference obtained is significant. Based on this result it can be understood that teachers who have a high need for professional development believe more in using technology more effectively in their classes.

\section{Discussion}

In this study, it was found that physics teachers believe that they need to develop their knowledge and skills on the use of technology in the classroom. It is emphasized that teachers in various branches have a positive attitude towards technology, but their ability to use basic computer programs and educational software in their classes is insufficient (Cure \& Ozdener, 2008). In a study conducted to determine the general competencies of primary education teachers in Turkey, it was found that teachers have a high level of IT technology knowledge, however, their knowledge and skills of computer programs that are compulsory for use in their classes are low (TEA, 2009). As a result of this research, it can be thought that teachers feel the need to have their knowledge and skills in this area developed because they do not find themselves competent in using technology in the classroom, likewise in integrating technology in to their lessons. 
In the study, physics teachers stated that the use of animation (Animation-Flash, etc.) and education software (applets) is necessary for improving physics education. It can be thought that teachers possess this view because they are aware of the educational software that offers the opportunity to visually understand many physics subjects or experiments. In their research, Erdem \& Uzal (2017) stated that physics teachers need professional development for the use of off-the-shelf animation software in teaching. It may be concluded that this result is parallel with the result of the research.

In the research, teachers expressed views on the support of technology for laboratories. It can be understood that teachers believe that laboratory experiments and activities should be carried out in order for students to fully understand physics topics. Based on traditional laboratory activities, it can be said that technology-based laboratory activities will contribute much more to learning.

In the study, teachers stated that all technologies of education should be further taken advantage of. With the implementation of Fatih Project in their schools, teachers may have expected various types of technological opportunities to be offered to them because they have saved time and benefitted from technology while using it to deliver their lessons.

Physics teachers stated that they want to use instructional software in their lessons and use written and visual texts from the internet. It has been determined that teachers want to use educational software in the educational process which is a positive tendency, however they feel that they do not have the ability to use the software at an adequate level because they do not have the ability to use the educational software effectively (Ozdener \& Imamoglu, 2005). In this study, it is seen that teachers want to improve technology-based physics education by using physics-related software in teaching and instructional materials from the internet. In some studies it is seen that teachers feel the need for professional development in order to know how to use information technologies in physics classes (Baser, Yesildere \& Ev, 2003; Erdem, Uzal \& Ersoy, 2004; Erdem, Uzal \& Ersoy, 2010; Erdem \& Uzal, 2017; Kaptan, 2004; Uzal, Erdem \& Ersoy, 2009; Ustuner, Erdem \& Ersoy, 2002) so it can be said that they want to improve technology-based physics education. These results also support the results of the study.

Teachers agreed to a minor extent while suggesting that a variety of software for use on Tablet PCs should be used. This may be because teachers do not believe much in the use of Tablet PCs in the classroom. In research by Erdem \& Uzal (2017) it can be seen that teachers need professional development to integrate software installed on Tablet PCs in to their lessons.

In the study, teachers stated that the use of LCD panels, Microcomputer Based Laboratories, Mobile Science Laboratories, Advanced calculators and the use of tablet PCs for teaching subjects is necessary. In some public high schools there are Mobile science laboratories and in most there are LCD panel technologies are available. However, in public high schools, there are no microcomputer assisted or advanced calculator assisted laboratory technologies. According to the researcher's observations, in most high schools with mobile science laboratories, laboratory activities are not able to be carried out with these devices because teachers do not have the knowledge and skills to carry out experimental activities, they do not have the experiment guides to assist them or help them take action. Teachers desire for the use of LCD panels in teaching course subjects found in the study, may suggest that teachers need professional development in this field. In some studies, it can be seen that the most important problem in the use of interactive whiteboards is that teachers lack knowledge and skills on this technological device (Smith, Higgins \& Wall, 2005; Somyurek, Atasoy \& Ozdemir, 2009), therefore teachers need professional development in this area and they made suggestions in the areas in which they also need professional development. It can be concluded that this result is similar to the research result.

In contrast to science and physics teachers not being aware of educational software, simulation programs, graphic calculators, etc. in the early 2000s, the physics teachers who participated in this study are aware of technology devices and want to use the said technology devices more in their lessons.

\section{Conclusion}

In this study to determine teachers' views on using technology to improve physics education, teachers strongly agree with the suggestions that; "teachers knowledge and skills on using technology in the classroom should be developed, Animation (Animation-Flash, etc.) and education software (applets) should be utilized, laboratories should be made technology-based, teaching software (Interactive Physics, i.e simulation programs) should be utilized, written and visual texts on the internet should be made use of and LCD panels (interactive boards) should be used in the classroom."

It was concluded that teachers agreed with the views of; "a variety of software prepared for use on Tablet PCs should be taken advantage of, microcomputer based laboratories should be made use of (MBL), Mobile Science Laboratories 
(Nova 5000 etc.) should be utilized, Tablet PCs and advanced (graphics and CAS) calculators should be used."

It is understood that teachers' views on the use of technology in improving physics education does not change according to the variables of gender, seniority year or computer literacy. On the other hand, it is understood that those with high professional development needs differed positively and significantly in their opinions from those whose needs are medium and low.

In accordance with these results, the following suggestions can be made:

- This research can be regarded as a pilot study and a more comprehensive study could be carried out with a wider sample across the country. In the same study, face-to-face interviews with teachers to be selected from the sample could provide more detailed information on the use of technology in order to improve physics education.

- Teachers should be offered professional development opportunities to improve their knowledge and skills on using the technological equipment in their schools (Tablet PCs, LCD panels, Microcomputer Based Laboratories, Mobile Science Laboratories, Advanced Calculators, etc.)

- Teachers should be given practical training in conducting technology-based physics experiments that can meet the goals of the 2018 High School Physics Curriculum Program (MNE, 2018).

- The digitalization of educational materials can improve the quality of teaching physics (Orleans, 2007). For this reason, teachers should be encouraged to develop technology-based teaching materials related to physics subjects and experiments.

- In schools, Information Technology teachers should be assigned who can guide other teachers in preparing technology-based physics course topics and experimental activities.

\section{References}

Aktas, I., Gokoglu, S., Turgut, Y. E., \& Karal, H. (2014). Teachers' views on the Fatih Project: Awareness, foresight and expectations. Necatibey Faculty of Education Journal of Electronic Science and Mathematics Education, 8(1), 257-286.

Atasoy, S., \& Akdeniz, A. R. (2007). The development and implementation of a test to determine misconceptions about Newton's laws of motion. Journal of Turkish Science Education, 4(1), 45-59.

Ayvaci, H. S., Bakirci, H., \& Basak, M. H. (2014). Evaluation of the problems in the implementation process of the Fatih Project by administrators, teachers and students. Yuzuncu Yil University, Faculty of Education, 11(1), 20-46.

Banoglu, K., Madenoglu, C., Uysal, S., \& Dede, A. (2014). Investigation of teachers' perceptions of FATIH project (Eskisehir Province Case). Journal of Educational Sciences Research, 4(1), 39-58. https://doi.org/10.12973/jesr.2014.40s3a

Baser, N., Yesildere, S., \& Ev, E. (2003). The perspectives of teachers on computer assisted education working in Curriculum Laboratory Schools. The Journal of Modern Education, 303, 30-36.

Batane, T., \& Ngwako, A. (2017). Technology use by pre-service teachers during teaching practice: Are new teachers embracing technology right away in their first teaching experience? Australasian Journal of Educational Technology, 33(1), 48-61.

Bilici, A. (2011, September). Teachers' views on the use of information technology devices in an educational context and their views on the Fatih Project in Education: Sincan provincial general assembly example. In 5th International Computer \& Instructional Technologies Symposium (pp. 22-24). Elazig-Turkey: Firat University.

Bozkurt, E., \& Sarikoc, A. (2008). Can the virtual laboratory in physics education replace the traditional laboratory? Selcuk University Journal of Ahmet Kelesoglu Education Faculty, 25, 89-100.

Buyukozturk, S. (2012). Data analysis Handbook for Social Sciences: Statistical Research Pattern, SPSS Applications and Interpretation (16th Edition) Ankara: PEGEM A Publishing.

Can, A. (2014). Quantitative data analysis in the process of scientific research with SPSS (2nd Ed.). Ankara: Pegem Academy.

Cepni, S. (2014). Introduction to research and project studies (7th Ed.). Trabzon: Celepler Printing.

Cure, F., \& Ozdener, N. (2008). Information and communication technologies (ICT) implementation achievements and ICT attitudes of teachers. Hacettepe Universiyi Faculty of Education Journal 34(34), 41-53. 
Daghan, G., Kibar, P. N., Akkoyunlu, B., \& Baskan, G. A. (2015). Approaches and views of teachers and managers towards the use of interactive whiteboards and tablet computers. Turkish Journal of Computer and Mathematics Education, 6(3), 399-417. https://doi.org/10.16949/turcomat.42868

Demir, S., Ozmantar, M. F., Bingolbali, E., \& Bozkurt, A. (2011, September). Review of technology use by classroom teachers. In 5th International Computer \& Instructional Technologies Symposium (pp. 922-928). Elazig, Turkey: Firat University.

Demircioglu, H., \& Geban, Ö. (1996). Comparison of computer assisted teaching and traditional problem solving activities in science education in terms of class success. Hacettepe University Faculty of Education Journal, 12(12), 183-185.

Dursun, O., Kuzu, A., Kurt, A., Gullupinar, F., \& Gultekin, M. (2013). Views of school administrators on the implementation process of the Fatih Project pilot. Trakya University Faculty of Education Journal, 3(1), 100-113.

Erdem, A., \& Uzal, G. (2017). Examination of the professional development needs of teachers in technology-based physics education in terms of some variables. Journal of International Social Research, 10(54), 710-718. https://doi.org/10.17719/jisr.20175434637

Erdem, A., \& Uzal, G. (2018). Administrative views on the use of technology to improve physics education in high schools. Journal of International Social Research, 11(55), 582-592. https://doi.org/10.17719/jisr.20185537231

Erdem, A., Uzal, G., \& Ersoy, Y. (2004, November). The views of a group of Science/Physics teachers on laboratory activities based on technology. IV. International Educational Technology Symposium, E-Transition in Education (proceedings Vol: II, 1124-1130). Sakarya, Turkey: Sakarya University.

Erdem, A., Uzal, G., \& Ersoy, Y. (2010). A group of Science/Physics Teachers' In-Service Training Needs. In Y. Ersoy, G. Uzal \& A. Erdem (Eds), Science/Physics Teaching-I: Expansions, Developments and New Approaches, (pp. 75-82). Ankara: Nobel Pub.

Ersoy, Y., Erdem, A., \& Uzal, G. (2010). Continuous Development of Science/Physics Teachers-I: Process of Change and Stages. In Y. Ersoy, G. Uzal \& A. Erdem (Eds), Science/Physics Teaching-II: Laboratory Activities, Experiments, (pp. 197-212). Ankara: Nobel Pub.

Gorhan, M. F., \& Oncu, S. (2015). Interactive Wood in the eyes of teachers and administrators: a case study on the perception of convenience of use and advantages. Journal of Teacher Education and Educators, 4(1), 53-77.

Gul, S., \& Yesilyurt, S. (2011). The effect of computer based instruction, based on a constructivist learning approach, on students' attitudes and achievements. Necatibey Education Faculty Electronic Science and Mathematics Education Journal, 5(1), 94-115.

Gulcicek, C., \& Yagbasan, R. (2004). Students misconceptions about conservation of mechanical energy in a simple pendulum system. Gazi University Gazi Education Faculty Journal, 24(3), 23-38.

Gunbayi, I., \& Yoruk, T. (2014). Views of managers and teachers on the stage of implementation of the Fatih Project in education (Sample from Muratpasa district in the city of Antalya) [Principals' and teachers' opinions on the use of the project FATIH in education]. - Journal of Educational Sciences Research, 4(1), 189-211. http://ebad-jesr.com/

Gurol, M., Donmus, V., \& Arslan, M. (2012). The views of primary school teachers on the Fatih Project. International Journal of Educational Technology, 3(3). Retrieved from http://www.idealonline.com.tr/IdealOnline/pdfViewer/index.xhtml?uId=75593\&ioM=Paper\&preview=true\&isVie wer=true\#pagemode $=$ bookmarks

Guven, G., \& Sulun, Y. (2012). The impact of computer based instruction in the 8th grade on academic achievement and students attitudes towads science and technology. Journal of Turkish Science Education, 9(1), 68-79.

Jimoyiannis, A., \& Komis, V. (2001). Computer simulations in physics teaching and learning: a case study on students' understanding of trajectory motion. Computers \& education, 36(2), 183-204.

https://doi.org/10.1016/S0360-1315(00)00059-2

Kaltakci, D., \& Didis, N. (2007, April). Identification of Pre-Service Physics Teachers' Misconceptions on Gravity Concept: A Study with a 3-Tier Misconception Test. In AIP Conference Proceedings (Vol. 899, No. 1, pp. 499-500). AIP.

Kaptan, F. (2004). A Study on the competencies of science teacher candidates in using technology. Contemporary Education Journal, 311, 39-43. 
Karamustafaoglu, M., Aydin, M., \& Ozmen, H. (2005). The effect of computer aided physics activities on student achievements: Simple harmonic motion example. TOJET, 4(4), 67-81.

Karasar, N. (1999). Scientific Research Method (9th Ed.). Ankara: Nobel Publication Distribution.

Kim, M., Choi, J., \& Song, J. (2007). Developing a web-based system for testing students' physics misconceptions (WEBSYSTEM) and its implementation. Journal of the Korean Association for Research in Science Education, 27(2), 105-119.

Kolcak, D. Y., Mogol, S., \& Unsal, Y. (2014). The Comparison of the laboratory method and computer simulation activities in the elimination of misconceptions in Physics teaching and concepts. Education and Science, 39(175), 154-171.

Lawrenz, F. (1986). Misconceptions of physical science concepts among elementary school teachers. School Science and Mathematics, 86(8), 654-660. https://doi.org/10.1111/j.1949-8594.1986.tb11669.x

MNE (2018). 9th, 10th, 11th and 12th Classroom Physics Curriculum. Retrieved January 9, 2019, from http://mufredat.meb.gov.tr/Dosyalar/201812103112910-orta\%C3\%B6\%C4\%9Fretim_fizik_son.pdf

NCETE (1985). A call for change in teacher education. Washington DC: AACTE Pub.

Orleans, A. V. (2007). The condition of secondary school physics education in the Philippines: Recent developments and remaining challenges for substantive improvements. The Australian educational researcher, 34(1), 33-54. https://doi.org/10.1007/BF03216849

Ornek, F., Robinson R. W., \& Haugan, P. M. (2008). What makes physics difficult? International Journal of Environmental and Science Education, 3(1), 30-34.

Ozdener, N., \& Imamoglu, C. (2005). Evaluation of MNE-in-service training courses in terms of gaining skills in software useage activities. IV. International Educational Technologies Symposium. Sakarya, Turkey: Sakarya University.

Pamuk, S., Cakir, R., Ergun, M., Yilmaz, H. B., \& Ayas, C. (2013). Use of tablet PC and interactive board from teacher and student perspective: Fatih Project Evaluation. Educational Sciences in Theory and Practice, 13(3), $1799-1822$.

Sarabando, C., Cravino, J. P., \& Soares, A. A. (2014). Contribution of a computer simulation to students' learning of the physics concepts of weight and mass. Procedia Technology, 13, 112-121.

https://doi.org/10.1016/j.protcy.2014.02.015

Smith, H. J., Higgins, S., Wall, K., \& Miller, J. (2005). Interactive whiteboards: boon or bandwagon? A critical review of the literature. Journal of Computer Assisted Learning, 21(2), 91-101. https://doi.org/10.1111/j.1365-2729.2005.00117.x

Somyurek, S., Atasoy, B., \& Ozdemir, S. (2009). Board's IQ: What makes a board smart? Computers \& Education, 53(2), 368-374. https://doi.org/10.1016/j.compedu.2009.02.012

Styer, D. F. (1996). Common misconceptions regarding quantum mechanics. American Journal of Physics, 64(1), 31-34. https://doi.org/10.1119/1.18288

Sugar, W., Crawley, F., \& Fine, B. (2004). Examining teachers' decisions to adopt new technology. Journal of Educational Technology \& Society, 7(4), 201-213.

Sung, H. W. F., \& Rudowicz, C. (2003). Physics behind the magnetic hysteresis loop-a survey of misconceptions in magnetism literature. Journal of magnetism and magnetic materials, 260(1-2), 250-260.

https://doi.org/10.1016/S0304-8853(02)01339-2

TEA (2009). Teacher Qualifications Summary Report. Turkish Education Association, Ankara: TEA.

Ustuner, I. S., Erdem, A., \& Ersoy, Y. (2002, September). Education of Science/Physics Teachers-I: Requirements and Activities. V. National Science and Mathematics Education Congress (Volume 2, pp. 1352-1357). Ankara, Turkiye: ODTU

Ustuner, I. S., Ersoy, Y., \& Sancar, M. (2000, September). Expectations of science/physics teachers from in-service training and symposiums. IV. Science Education Congress Papers Book (pp. 311-316). Ankara, Turkey: HU Education Faculty.

Uzal, G., Erdem, A., \& Ersoy, Y. (2009). Computer Based Science/Physics Education: General trends and requirements of teachers. Journal of National Education, 183, 380-390. 
Van Hise, Y. A. (1988). Student misconceptions in mechanics: An international problem? The Physics Teacher, 26(8), 498-502. https://doi.org/10.1119/1.2342598

Wang, J. Y., Wu, H. K., \& Hsu, Y. S. (2017). Using mobile applications for learning: Effects of simulation design, visual-motor integration, and spatial ability on high school students' conceptual understanding. Computers in Human Behavior, 66, 103-113. https://doi.org/10.1016/j.chb.2016.09.032

Windschitl, M., \& Andre, T. (1998). Using computer simulations to enhance conceptual change: The roles of constructivist instruction and student epistemological beliefs. Journal of Research in Science Teaching: The Official Journal of the National Association for Research in Science Teaching,35(2), 145-160. https://doi.org/10.1002/(SICI)1098-2736(199802)35:2<145::AID-TEA5>3.0.CO;2-S

Yildiz, A., \& Buyukkasap, E. (2006). Misconceptions on Force and motion comcepts of Physics Students and Predictions of Instructors on this Subject. Hacettepe University Faculty of Education Journal, 30(30), 268-277.

Zeilik, M., Schau, C., \& Mattern, N. (1998). Misconceptions and their change in university-level astronomy courses. The Physics Teacher, 36(2), 104-107. https://doi.org/10.1119/1.880056

Zengin, R. (2005). English teachers' use of tools and Technology and their competency throughout Anatolian High Schools in Istanbul (Unpublished doctoral dissertation). Istanbul University Institute of Social Sciences, İstanbul, Turkey.

\section{Copyrights}

Copyright for this article is retained by the author(s), with first publication rights granted to the journal.

This is an open-access article distributed under the terms and conditions of the Creative Commons Attribution license which permits unrestricted use, distribution, and reproduction in any medium, provided the original work is properly cited. 